\title{
PRIMARY PROCEDURE FOR ANORECTAL MALFORMATIONS IN CHILDREN; A SINGLE CENTER EXPERIENCE
}

\author{
Tariq Waheed, Sajjad Ali, Muhammad Uzair, Inayat Ur Rehman \\ Department of Paediatric Surgery Khyber Teaching Hospital, Peshawar - Pakistan
}

\begin{abstract}
Objective: To share our experience with outcome of primary procedure for anorectal malformation (ARM) in children.

Material \& Mathods: This Retrospective study included 40 patients from both genders who were operated in between January 2018 and January 2019 for high and intermediate ARM in the department of pediatric surgery Khyber Teaching Hospital Peshawar. Patients with common cloaca and associated life-threatening anomalies were excluded. Demographic and clinical data were tabulated and analyzed. The cost of the procedure was recorded in Pakistani Rupees and hospital stay in days. Continence was evaluated by Kelly's score and parents' satisfaction graded by Likert scale.
\end{abstract}

Results: Male to female ratio was 1.6:1. Mean hospital stay was $5.91 \pm 1.01$ days and mean cost was $22950 \pm 3234$ Pakistani Rupees. Wound dehiscence was recorded in $3(7.5 \%), 2$ (5.0\%) patients developed surgical site infection and $11(35.48 \%)$ patients who had perianal excoriation. Adhesive obstruction and mucosal prolapse were seen in $1(2.5 \%)$ patient each while anal stenosis in 2(5.0\%) Patients. After 6 months 28 (70\%) patients had formed stools while $12(30 \%)$ had loose stools. Stool frequency was 0-1 time/day in majority i.e. 20 (50 \%) patients. Continence was fair in $24(60 \%)$ patients. Parents of $20(50 \%)$ patients were very satisfied, $17(42.5 \%)$ satisfied only. Continence for age and sex revealed insignificant $P$ values of 0.213 and 0.07 respectively.

Conclusion: Primary procedure for anorectal malformations may be a good alternative to traditional three-stage procedure in selected patients with intermediate and high variety of ARM.

Keywords: Anorectal malformation (MeSH); Abdominoperineal pull through (Non-MeSH); Kelly's score (Non-MeSH).

This article may be cited as: Waheed T, Ali S, Uzair M , Rehman UI. Primary procedure for anorectal malformations in children; A single center experience. J Med Sci 2021 January;29(1):21-25

\section{INTRODUCTION}

Anorectal malformations (ARMs), encompass a wide range of congenital anomalies of the terminal part of the gastrointestinal tract. With an approximate incidence of 1 in 2000 to 1 in 5000 live births and slight male predominance, the anomalies range from trivial malpositioning of the anus with a good functional prognosis to extremely complicated anatomical deviation of the hind gut and urogenital system ${ }^{1,2}$. Depending upon the location of the blind end of distal gut above, within, or below the Levator muscle ARMs were respectively classified as high, intermediate, or low by Wingspread. The in fashion Krickenbeck classification is not just a diagnostic tool for categorizing the malformations but also helps in assessing the prognosis after treatment ${ }^{3}$.

\section{Correspondence}

Dr Sajjad Ali

Senior Registrar

Department of Paediatric Surgery

Khyber Teaching Hospital, Peshawar - Pakistan

Email: sajjadbuneri@gmail.com

Cell: +92-332-9941534

Date received: $\quad 06-07-2020$

Date revised: $\quad 13-08-2020$

Date accepted: 25-03-2021
Diagnostic workup for anorectal malformation includes a formal history, thorough examination of the perineum, and where needed $x$-ray cross table/invertogram. Good centers even do MRI and ultrasound of the perineum ${ }^{4}$. These unfortunate newborns in a significant proportion suffer from the consequences of associated anomalies as well, of which urogenital malformations predominate. The co-existence of congenital cardiac and vertebral distortions is also not uncommon. Echocardiography, ultrasound for urogenital anatomy, and lumbosacral radiography are important before planning intervention ${ }^{5}$.

Regarding its treatment different surgical centers have different approaches based on the variety of anomalies and experience of surgeons. Simple anomalies like perineal fistulae are dealt with primarily. Regarding others, there is no absolute consensus recommendation. However, both single-stage and three-stage repairs are in practice ${ }^{4}$. The supporters of the single-stage procedure claim low morbidity, low mortality, and low cost. The counter-argument on the issue of continence is its attribution to the development of cerebral fibers which develop by the end of the first year of life. As there is no pouchitis and tissue planes are virgin perineal dissection becomes technically feasible and easier. Moreover, the social resistance to sto- 
ma is not encountered and hence no bowel preparation is needed. Other notable benefits are less physical and psychosocial stress to the parents, child, and surgeon which makes it a considerable option. In antagonism to the opinion are surgeons who rightly fear the endangered urogenital system in primary repair 6 . Moreover, handling the underdeveloped pelvirectal musculature is a demanding job.

In Pakistan most centers favor the traditional 3 stage procedure ${ }^{7}$. But in a developing country, where socio-economic problems and insufficient infrastructure are unavoidable concerns, the outcome of primary definitive abdominoperineal pull through and primary posterior sagittal anorectopexy/anterior sagittal anorectopexy needed evaluation. So here we are with our experience with single-stage procedure for ARMs in selected patients.

\section{MATERIAL AND METHODS}

This retrospective study was conducted in the department of Paediatric surgery Khyber teaching hospital Peshawar. After formal ethical approval from the Institutional Review and ethical approval board, operative, post-operative and follow-up records of patients who had a primary procedure for ARM between Jan 2018 to Jan 2019 were retrieved. 40 subjects from both sexes qualified for the study applying inclusion and exclusion criteria. Irrespective of the type of ARM Patients with severe life-threatening other congenital malformations, sepsis or necrotizing enterocolitis with pneumoperitoneum, extreme prematurity, and common cloacae were excluded as they are known contraindications to primary repair?

Patients operated for any indication elsewhere were also excluded. Primary definitive operations included Primary PSARP in female patients with recto vestibular fistula, imperforate anus without fistula in both males and females, primary abdominoperineal pull-through for high anorectal atresia, rectovaginal fistula in females, and recto urinary fistula in males.

Demographic features documented in patients' files, intraoperative findings, and postoperative complications were tabulated. The cost of the procedure in Pakistani Rupees was calculated from the cash memo which included cash spent on surgical and medical stuff only. Hospital stay in days was counted from the date of admission till the date of discharge. Follow-up variables were obtained from the record. Continence was evaluated by Kelly's score from the available 6 months follow up data and parents' satisfaction graded by the Likert scale.

The data was entered into SPSS version 20, computer program, and analyzed accordingly. Study variables were analyzed by simple descriptive statistics. Mean and the standard deviation was calculated for numerical variables. Frequency and percentage were calculated for gender, intraoperative findings and postoperative out- come of primary PSARP/abdominoperineal pull-through maintained at follow-up after month 6 . Age at the time of surgery and gender were then evaluated for continence and a p-value was generated. P-value of less than 0.05 was considered for significance.

\section{RESULTS}

All surgeries were completed in one go and no case was converted to alternate surgery. We did not encounter any mortality. Characteristics of patients are shown in Table I. The male to female ratio was 1.6:1, operative outcome depicted a mean operative time of 102 minuets, mean hospital stay of 5.91 days, the mean cost of 22950 Pakistani Rupees(PKR), and complications as listed in Table II.

As tabulated in Table 2, 3 (7.5\%) patients developed perianal wound dehiscence, 2 (5.0\%) patients had surgical site infection,11 (35.48\%) patients suffered from perianal excoriation, adhesive obstruction, and mucosal prolapse were seen in 1 (2.5\%) patient each while anal stenosis in 2(5.0\%) Patients. Functional outcome in terms of stool consistency, frequency and continence following Kelly's criteria at 6th-month post-primary procedures for ARMs as per record are shown in table 3.

Parents' satisfaction evaluated via a Likert scale is shown table IV. When continence was checked for age and sex as shown in table $\mathrm{V}$, the chi-square test revealed insignificant $P$ values of 0.213 and 0.07 respectively.

Table 1: Characteristics of patients

\begin{tabular}{|c|c|c|}
\hline \multirow{2}{*}{ Age (months) } & Mean \pm SD & $1.42 \pm 0.76$ \\
\cline { 2 - 3 } & Range & $0-6$ months \\
\hline \multirow{2}{*}{ Gender } & Male & $25(62.5 \%)$ \\
\cline { 2 - 3 } & Female & $15(37.5 \%)$ \\
\hline Weight (Kg) & Mean \pm SD & $3.89 \pm 0.42$ \\
\hline \multicolumn{2}{|c|}{ Any other congenital abnormality } & $0(0.0 \%)$ \\
\hline \multirow{2}{*}{$\begin{array}{c}\text { Past history of } \\
\text { surgery }\end{array}$} & Yes & $0(0.0 \%)$ \\
\cline { 2 - 3 } & No & $40(100.0 \%)$ \\
\hline
\end{tabular}

Table 2: Operative outcomes

\begin{tabular}{|c|c|}
\hline Operative outcomes & No. of patients (\%) \\
\hline Operative time & $102 \pm 20.67 \mathrm{~min}$ \\
\hline Mean hospital stay (days) & $5.91 \pm 1.01$ \\
\hline Perianal wound dehiscence & $3(7.5 \%)$ \\
\hline Surgical site infection & $2(5.0 \%)$ \\
\hline Perianal excoriation & $11(35.48 \%)$ \\
\hline Adhesive obstruction & $1(2.5 \%)$ \\
\hline Mucosal prolapse & $1(2.5 \%) \mathrm{h}$ \\
\hline Anal stenosis & $2(5.0 \%)$ \\
\hline Cost of the procedure & $22950 \pm 3234 \mathrm{PKR}$ \\
\hline
\end{tabular}


Primary Procedure For Anorectal Malformations In Children; A Single Center Experience.

Table 3: Functional outcome

\begin{tabular}{|c|c|c|}
\hline \multicolumn{2}{|c|}{ Parameters } & At 6th month \\
\cline { 2 - 3 } Stool consistency & Liquid & $\mathrm{n}(\%)$ \\
\cline { 2 - 3 } & Loose & $0(0.0 \%)$ \\
\cline { 2 - 3 } & Formed & $12(30 \%)$ \\
\hline \multirow{2}{*}{ Stool frequency } & 0 to 1 & $28(70 \%)$ \\
\cline { 2 - 3 } & 2 to 3 & $11(27.5 \%)$ \\
\cline { 2 - 3 } & More than 3 & $9(22.5 \%)$ \\
\hline \multirow{2}{*}{ Continence } & Good & $10(25 \%)$ \\
\cline { 2 - 3 } & Fair & $24(60 \%)$ \\
\cline { 2 - 3 } & Poor & $6(15 \%)$ \\
\hline
\end{tabular}

Table 4: Parents' satisfaction

\begin{tabular}{|l|c|c|}
\hline Parents' satisfaction & Unsatisfied & $\mathbf{3}(\mathbf{7 . 5 \% )}$ \\
\cline { 2 - 3 } & Satisfied & $17(42.5 \%)$ \\
\cline { 2 - 3 } & Highly satisfied & $20(50 \%)$ \\
\hline
\end{tabular}

Table 5: Continence for Age and Gender

\begin{tabular}{|c|c|c|c|c|c|}
\hline & & \multicolumn{3}{|c|}{ Continence } & \multirow[t]{2}{*}{$P *$ value } \\
\hline & & Good & Fair & Poor & \\
\hline \multirow[t]{3}{*}{ Age } & $\begin{array}{l}\text { Less than } \\
\text { one month }\end{array}$ & 6 & 17 & 6 & \multirow[t]{3}{*}{$0.213^{\star *}$} \\
\hline & $\begin{array}{l}\text { One month } \\
\text { to } 6 \text { months }\end{array}$ & 4 & 7 & 0 & \\
\hline & Total & 10 & 24 & 6 & \\
\hline & & \multicolumn{3}{|c|}{ Continence } & \multirow[t]{2}{*}{$\mathrm{P}^{*}$ value } \\
\hline & & Good & Fair & Poor & \\
\hline \multirow[t]{3}{*}{ Gender } & Male & 5 & 14 & 6 & \multirow[t]{3}{*}{$0.07^{* *}$} \\
\hline & Female & 5 & 10 & 0 & \\
\hline & Total & 10 & 24 & 6 & \\
\hline
\end{tabular}

${ }^{*}$ chi square test

** Not significant

\section{DISCUSSION}

Countries with poor econom where the socioeconomic status of the people is not satisfactory, the quality of health care is compromised. In such regions of the world, the traditional three stages of surgical management of ARMs i.e. Colostomy followed by PSARP and then closure of stoma mean a costly policy both in terms of money and time. The idea sounds further irrelevant when the psychosocial surrounding considers the anomaly and colostomy as a stigma. The psychological stress of parents cannot be avoided at the cost of a long and tiring surgical where continence is never a promise. Above all these recognized complications of a colostomy should always be kept in mind $^{8}$. The incidence of these complications has been reported in the literature from $28 \%$ to $74 \%{ }^{10}$. When prosperous countries initiated primary (one-stage) PSARP in selected neonates, it was found as feasible and safe alternative ${ }^{10}$. The main consideration in one go strategy has always been the uncertain endangered urogenital anatomy. Therefore, literature favoring the classic strategy has questioned the functional outcome of the single-step surgery in $\mathrm{ARM}^{6}$. The socioeconomic status of the people in this part of the world and questionable results of the three-stage procedure in terms of functional outcome were sufficient indications to share our local experience with single-stage correction for ARM.

Sharing our findings and results of a retrospective analysis of a one-stage procedure, the mean age of patients was 1.42 \pm 0.76 months (Range: 0-6 months) with male predominance. In a study by Osifo OD, all patients were neonates with male to female ratio of $1.5: 1^{10}$. Similarly literature reveals prospective and retrospective studies on single stage procedure for anorectal malformations both in neonatal period and later. Also, there are separate studies about this modality of treatment and its outcome exclusively in male and female patients ${ }^{6,11}$.

In our study, the mean operative time was 102 minuets which is close to the operative time experienced by Upadhyaya VD (110 min $)^{12}$ though it was just 50 minutes in a study by Ibrahim $I A^{13}$. Hospital stay from the date of admission till discharge was 5.91 days in this study. In other studies, mean hospital stay of 7 to 9 days has been recorded $^{10,17}$.

Perianal wound dehiscence in our study was observed in $7.5 \%$ of patients. Among these 3 patients, two were Post PSARP females and 1 post abdominoperineal pull-through male. All these patients were conservatively managed and dehiscence responded to hygiene measures and pyodine wash. Contrary to our finding wound dehiscence was $0 \%$ in a study conducted by Menon $\mathrm{P}^{14}$. The figure was $5 \%$ in a study published in the July 2010 issue of Journal of Pediatric surgery and about $40 \%$ in a randomized control trial conducted by Gupta $A^{15,18}$. We noticed surgical site infection in $6.25 \%$ of our patients through the percentage was $2 \%$ in a study by Osifo OD and $30 \%$ in that by Amanollahi $\mathrm{O}^{10,16}$. The most common early complication was perineal excoriation it was not seen in any patient in a similar study by Albanese $\mathrm{CT}^{17}$.

Only one patient in our study developed adhesive intestinal obstruction and reported one month after surgery with abdominal distension and bilious vomiting. This was a post abdominoperineal pull-through a male patient with recto urethral fistula. The patient responded to our conservative treatment. Stenosis of the neontal anus and mucosal prolapse are other recognized complications after surgery for ARM ${ }^{16,17,18}$. Two patients developed anal stenosis during initial post-operative months due to noncompliance with the dilatation program. In both cases, dilatation was done under general anesthesia and parents counseled to ensure compliance. One patient reported mucosal prolapse which was surgically trimmed. 
The incidence of Congenital anomalies is higher in newborns of parents of low socioeconomic status. The financial aspect is thus an important consideration in developing countries. The total cost of surgical stuff and medicine was calculated from invoices. It was important because in developing countries finances are always a problem for poor parents in public sector hospitals even. The mean spent cost was 22950 Pakistani Rupees exclusive of food and travel expenses. This may vary from country to country and currency to currency but gives a rough idea of its affordability and reference for comparison with three stage procedure. Recent literature favors single-stage procedure over conventional three-stage approach as far finances in a developing country are concerned ${ }^{16,18}$.

Parents' satisfaction is a subjective variable but is very important because the child with outcome ultimately belongs to parents and they have definite expectations. We tried to standardize parents' satisfaction by using the Likert scale. The results on this scale at follow-up depicted that parents of 20 children (50\% of the total) were fully satisfied and those of 17 children (42.5\%) were partially satisfied only. Parents of 3 children (7.5\%) were not happy with the surgical and functional outcome. However please note that parents' satisfaction is a subjective measurement and results are highly variable in the literature on the same parameters ${ }^{19,20}$.

The functional outcome has always been one of the most important concerns and quality of life determinant in subjects under consideration post-treatment. The stooling pattern in terms of frequency and consistency has been used as a tool to assess the bowel function and continence post-surgical procedures on patients with ARM. Our study revealed formed stools in $70 \%$ of children and a frequency of 0 to 1 time/day in 50 percent of post operative children on follow-up at 6 months. According to literature, a normal stooling pattern is about 3 to 6 times per day at birth which decreases to 0 to 2 times per day by the end of the second month and remains so till 2 years of age $^{16}$. Moreover there are some methods to evaluate any fecal incontinence in a reproducible method after a corrective intervention. Among these standardized methods, Kelly's criteria is the simplest of all scoring systems and is applicable with reproducible results even in a 3-month infant ${ }^{16,18,21}$. Since all subjects were below the age of toilet training, Kelly's criteria suited our study the most to evaluate continence. We found that $25 \%$ of our patients exhibited good continence, $60 \%$ fair continence while in $15 \%$ of patients the continence was poor according to our chosen criteria. Though continence is subject to the type of anomaly and improves with age, our findings of continence six months after primary partially are comparable to those mentioned in literature with acceptable variations ${ }^{16,18}$. Correlation of age at the time of surgery and gender with continence revealed statistically insignificant result $(P<0.05)$.
Sex of patient has been consistantly declared not related to functional outcome but the relation of age at the time of surgery to continence has been a subject of debate based on evidences ${ }^{10,16,18,22}$.

Stratification of the type of anomaly is not done in the study which can affect the results. Randomized control trial of single-stage vs three-stage procedure for ARM should be carried out to compare the outcome variables. Long term follow up of patients after single-stage procedure should be done for better evaluation of functional outcome at the age of toilet training and beyond.

\section{CONCLUSION}

Surgical treatment of anorectal malformation via traditional three-stage procedure has been a famous approach, but considering the psychosomatic trauma to the parents and patients, non-reproducible continence and cost of the procedure single-stage procedure may be a good alternative.

\section{RERERENCES}

1. Ahmed W, Dey D, Farid R. Prevalence and Pattern of Congenital Anomalies and Its Outcome at Chattagram Maa-O-Shishu General Hospital. JCMOSHMC. 2017;16(1):22-5.

2. Merwe E, Cox S, Numanoglu A. Anorectal malformations, associated congenital anomalies and their investigation in a South African setting. Pediatr Surg Int. 2017;33(8):875-82.

3. Makrufardi F, Arifin DN, Afandy D, Yulianda D, Dwihantoro A. Anorectal malformation patients' outcomes after definitive surgery using Krickenbeck classification: A cross-sectional study. Heliyon. 2020 Feb 1;6(2):e03435.

4. Morandi A, Ure B, Leva E, Lacher M. Survey on the management of anorectal malformations (ARM) in European pediatric surgical centers of excellence. Pediatric surgery international. 2015 Jun 1;31(6):543-50.

5. Wang C, Li L, Cheng W. Anorectal malformation: the etiological factors. Pediatric surgery international. 2015 Sep 1;31(9):795-804.

6. Gangopadhyay AN, Pandey V. Anorectal malformations. Journal of Indian Association of Pediatric Surgeons. 2015 Jan;20(1):10.

7. Qazi SH, Faruque AV, Khan MA, Saleem U. Functional outcome of anorectal malformations and associated anomalies in era of Krickenbeck classification. JCPSP: J Coll Physicians Surg Pak. 2016;26(3):204.

8. Menon P, Rao KL, Sinha AK, Lokesha K, Samujh R, Mahajan JK, Kanojia RP, Bawa M. Anorectal malformations in males: Pros and cons of neonatal versus staged reconstruction for high and intermediate varieties. Journal of Indian Association of Pediatric Surgeons. 2017 Apr;22(2):83.

9. Nour S, Beck J, Stringer MD. Colostomy complications in infants and children. Annals of the Royal College of Surgeons of England. 1996 Nov;78(6):526. 
10. Osifo OD, Osagie TO, Udefiagbon EO. Outcome of primary posterior sagittal anorectoplasty of high anorectal malformation in well selected neonates. Nigerian journal of clinical practice. 2014;17(1):1-5.

11. Adeniran JO, Abdur-Rahman L. One-stage correction of intermediate imperforate anus in males. Pediatric surgery international. 2005 Feb 1;21(2):88-90.

12. Upadhyaya VD, Gangopadhyay AN, Pandey A, Kumar V, Sharma SP, Gopal SC, Gupta DK, Upadhyaya A. Single-stage repair for rectovestibular fistula without opening the fourchette. Journal of pediatric surgery. $2008 \mathrm{Apr}$ 1;43(4):775-9.

13. Ibrahim IA, Korany M, Ammar SA. One stage posterior anal transposition for low and intermediate anorectal anomalies in females. Ann Pediatric Surg. 2007 Apr 1; 3:92-6.

14. Menon P, Rao KL. Primary anorectoplasty in females with common anorectal malformations without colostomy. Journal of pediatric surgery. 2007 Jun 1;42(6):1103-6.

15. Kuijper CF, Aronson DC. Anterior or posterior sagittal anorectoplasty without colostomy for low-type anorectal malformation: how to get a better outcome? Journal of pediatric surgery. $2010 \mathrm{Jul}$ 1;45(7):1505-8.

16. Amanollahi $\mathrm{O}$, Ketabchian $\mathrm{S}$. One-stage vs. three-stage repair in anorectal malformation with recto vestibular fistula. African journal of paediatric surgery: AJPS. 2016 Jan;13(1):20.

17. Albanese CT, Jennings RW, Lopoo JB, Bratton BJ, Harrison MR. One-stage correction of high imperforate anus in the male neonate. Journal of pediatric surgery. 1999 May 1;34(5):834-6.

18. Gupta A, Agarwala S, Sreenivas V, Srinivas M, Bhatnagar V. Primary definitive procedure versus conventional three-staged procedure for the management of low-type anorectal malformation in females: A Randomized controlled trial. Journal of Indian Association of Pediatric Surgeons. 2017 Apr;22(2):87.
19. Wigander H, Öjmyr-Joelsson M, Frenckner B, Wester T, Nisell M. Impact of Low Anorectal Malformation on Parenting Stress: A Mixed-Method Study. Journal of pediatric nursing. 2018 Sep 1;42: e45-51.

20. Lane VA, Nacion KM, Cooper JN, Levitt MA, Deans KJ, Minneci PC. Determinants of quality of life in children with colorectal diseases. Journal of pediatric surgery. 2016 Nov 1;51(11):1843-50.

21. Rigueros Springford L, Connor MJ, Jones K, Kapetanakis VV, Giuliani S. Prevalence of active long-term problems in patients with anorectal malformations: a systematic review. Diseases of the Colon \& Rectum. 2016 Jun 1;59(6):570-80.

22. Nam SH, Kim DY, Kim SC. Can we expect a favorable outcome after surgical treatment for an anorectal malformation? Journal of pediatric surgery. 2016 Mar $1 ; 51(3): 421-4$.

CONFLICT OF INTEREST: Authors declare no conflict of interest

GRANT SUPPORT AND FINANCIAL DISCLOSURE: NIL

\section{AUTHOR'S CONTRIBUTION}

Following authors have made substantial contributions to the manuscript as under

Waheed T: Conception \& final approval

Ali S: $\quad$ Design,Data collection and proof reading

Uzair M: Design and Statistical analysis

Rehman IU: Proof reading and final approval.

Authors agree to be accountable for all aspects of the work in ensuring that questions related to the accuracy or integrity of any part of the work are appropriately investigated and resolved. 